\title{
Best practices for physical activity programs and behavior counseling in older adult populations
}

\author{
M. E. Cress • D. M. Buchner • T. Prohaska • \\ J. Rimmer • M. Brown • C. Macera • L. DePietro • \\ W. Chodzko-Zajko
}

Published online: 13 April 2006

(C) EGREPA 2006

Publication Note All National Blueprint Publications are in the public domain and can be freely reproduced without copyright. This article has been previously published in Medicine Science and Sports and Exercise and the Journal of Aging and Physical Activity. Individuals or organizations who wish to publish National Blueprint articles should contact the National Blueprint Office for permission.

\section{E. Cress}

Department of Exercise Science,

University of Georgia,

Athens, GA, USA

D. M. Buchner

Division of Physical Activity and Nutrition,

Centers for Disease Control and Prevention,

Atlanta, GA, USA

T. Prohaska

School of Public Health,

University of Illinois at Chicago,

Chicago, IL, USA

J. Rimmer

Department of Disability and Human Development,

University of Illinois at Chicago,

Chicago, IL, USA

M. Brown

Physical Therapy Program,

School of Health Professions,

University of Missouri,

Columbia, MO, USA

C. Macera

Graduate School of Public Health,

San Diego State University,

San Diego, CA, USA

L. DePietro

Yale University,

New Haven, CT, USA

W. Chodzko-Zajko ( $\square)$

University of Illinois,

Champaign-Urbana, IL, USA

e-mail: wojtek@zajko.org

\begin{abstract}
Physical activity offers one of the greatest opportunities for people to extend years of active independent life and reduce functional limitations. The purpose of this paper is to identify key practices for promoting physical activity in older adults, with a focus on older adults with chronic disease or low fitness and those with low levels of physical activity. Key practices identified in promotion activity in older adults include: (1) a multidimensional activity program that includes endurance, strength, balance, and flexibility training is optimal for health and functional benefits; (2) principles of behavior change, including social support, selfefficacy, active choices, health contracts, assurances of safety, and positive reinforcement, enhance adherence; (3) management of risk by beginning at low intensity but gradually increasing to moderate physical activity which has a better risk/benefit ratio should be the goal for older adults; (4) an emergency procedure plan is prudent for community-based programs; and (5) monitoring aerobic intensity is important for progression and for motivation. Selected content reviews of physical activity programming from major organizations and institutions are provided. Regular participation in physical activity is one of the most effective ways for older adults, including those with disabilities, to help prevent chronic disease, promote independence, and increase quality of life in old age.
\end{abstract}

Keywords Aging - Quality of life · Exercise · Functional limitations

\section{Introduction}

A substantial body of scientific evidence that indicates regular physical activity can bring dramatic health benefits to people of all ages and abilities, and these 
benefits extend over the entire life. Physical activity offers one of the greatest opportunities to extend years of active independent life, reduce disability, and improve the quality of life for midlife and older persons $[6,28,30]$. Table 1 summarizes some of the many benefits associated with regular participation in physical activity.

Unfortunately, simply disseminating information about the health benefits of moderate physical activity does not appear to be sufficient in terms of increasing

Table 1 Health benefits of regular physical activity

\begin{tabular}{|c|c|}
\hline Health issue & Benefits of physical activity \\
\hline Cardiovascular health & $\begin{array}{l}\text { Improves myocardial performance } \\
\text { Increases peak diastolic filling } \\
\text { Increases heart muscle contractility } \\
\text { Reduces premature ventricular } \\
\text { contractions } \\
\text { Improves blood lipid profile } \\
\text { Increases aerobic capacity } \\
\text { Reduces systolic blood pressure } \\
\text { Improves diastolic blood pressure } \\
\text { Improves endurance } \\
\text { Improves muscle capillary blood flow }\end{array}$ \\
\hline Body composition & $\begin{array}{l}\text { Decreases abdominal adipose tissue } \\
\text { Increases muscle mass }\end{array}$ \\
\hline Metabolism & $\begin{array}{l}\text { Increases total energy expenditure } \\
\text { Improves protein synthesis rate and } \\
\text { amino acid uptake into the skeletal } \\
\text { muscle } \\
\text { Reduces low-density lipoproteins } \\
\text { Reduces cholesterol/very low-density } \\
\text { lipoproteins } \\
\text { Reduces triglycerides } \\
\text { Increases high-density lipoproteins } \\
\text { Increases glucose tolerance }\end{array}$ \\
\hline Bone health & $\begin{array}{l}\text { Slows decline in bone mineral } \\
\text { density } \\
\text { Increases total body calcium, } \\
\text { nitrogen }\end{array}$ \\
\hline $\begin{array}{l}\text { Psychological } \\
\text { well-being }\end{array}$ & $\begin{array}{l}\text { Improves perceived well-being and } \\
\text { happiness } \\
\text { Decreases levels of stress-related } \\
\text { hormones } \\
\text { Improves attention span } \\
\text { Improves cognitive processing speed } \\
\text { Increases slow wave and rapid eye } \\
\text { movement sleep }\end{array}$ \\
\hline $\begin{array}{l}\text { Muscle weakness and } \\
\text { functional capacity }\end{array}$ & $\begin{array}{l}\text { Reduces risk of musculoskeletal } \\
\text { disability } \\
\text { Improves strength and flexibility } \\
\text { Reduces risk of falls } \\
\text { Improves dynamic balance } \\
\text { Improves physical functional } \\
\text { performance }\end{array}$ \\
\hline
\end{tabular}

For more details, refer to Singh [27] participation among older adults [13]. To effect longterm changes in behavior, it is necessary to identify, examine, and begin to address the barriers to physical activity that prevent older adults from making the transition from sedentary to physically active [12]. On May 1, 2001, a coalition of national organizations released a major planning document designed to develop a national strategy for the promotion of physically active lifestyles among the midlife and older adult population. The National Blueprint: increasing physical activity among adults age 50 and older was developed with input from multiple organizations with expertise in medicine, social and behavioral sciences, epidemiology, public health, public policy, and environmental issues [24].

The major goals of this blueprint were to identify the primary barriers to participation in physical activity by people in their midlife and older adults, and to recommend specific strategies for overcoming them.

The National Blueprint identifies barriers to physical activity in the areas of research, home and community programs, medical systems, public policy and advocacy, and marketing and communications. It also proposes a number of concrete strategies for overcoming these barriers in society at large.

In response to one of the top priority strategies identified in the National Blueprint-to disseminate clearly articulated information to practitioners and lay leaders on best practices and guidelines for physical activity programs in the older adult population-a coalition of national organizations led by the American College of Sports Medicine (ACSM) developed an overview of best practices, guidelines, and recommendations regarding physical activity for older adults. This overview is presented in this study in three sections: (1) key components of a physical activity program, (2) strategies for addressing behavior change, and (3) injury and risk management in general programming and for specific chronic conditions and/ or disabilities.

\section{Section 1: key components of physical activity programs for older adults}

For general health and well-being, a well-rounded physical activity program should include endurance, strength, balance, and flexibility (Table 2). Most sedentary individuals will prefer and should be encouraged to begin with low-intensity physical activity. These activities should be tailored to the individual's specific needs and interests to ensure maximal enjoyment and optimize adherence to the physical activity 
Table 2 Components of fitness programs and physical activity

\begin{tabular}{|c|c|c|c|c|c|}
\hline & Lifestyle & Endurance $^{1}$ & Strength & Flexibility & Balance \\
\hline $\begin{array}{c}\text { Frequency } \\
\text { (days/ } \\
\text { week) }\end{array}$ & $5-7$ & $5-7$ & 2 or 3 & $2-3$ & $1-7$ \\
\hline Intensity & Moderate & $\begin{array}{l}\text { 12-14 RPE } \\
\text { 'somewhat hard' } \\
40 \text { to } 60 \% \\
\text { Estimated HR } \\
\text { max }\end{array}$ & $\begin{array}{l}\text { Resistance to } \\
\text { movement that } \\
\text { overloads with } \\
\text { greater resistance } \\
\text { have a greater effect }\end{array}$ & $\begin{array}{l}\text { To point of resistance } \\
\text { or mild discomfort }\end{array}$ & $\begin{array}{l}\text { Progress difficulty by } \\
\text { decreasing the } \\
\text { support as } \\
\text { competence } \\
\text { increases }\end{array}$ \\
\hline Volume & $\begin{array}{l}\text { Accumulate } \\
\text { at least } 30 \\
\text { min in } \\
\text { bouts of } 10 \\
\text { min or } \\
\text { longer }\end{array}$ & At least $30 \mathrm{~min}$ & $\begin{array}{l}\text { Two to three sets; } 10- \\
12 \text { repetitions; four } \\
\text { upper (biceps, } \\
\text { shoulder flexion, } \\
\text { chest press, and back } \\
\text { row) and four lower } \\
\text { body (hamstrings, } \\
\text { quadriceps, leg press, } \\
\text { and calves) }\end{array}$ & $\begin{array}{l}10 \text { to } 30 \text { s progressing } \\
\text { longer if desired. } \\
\text { Repeat three to } \\
\text { four times for each } \\
\text { stretch. Areas to } \\
\text { include, e.g., chest, } \\
\text { neck ROM, } \\
\text { hamstrings, } \\
\text { quadriceps and hip } \\
\text { flexors, calf soleus } \\
\text { and gastrocnemius, } \\
\text { hands, and triceps }\end{array}$ & $\begin{array}{l}\text { Dynamic, focus on } \\
\text { mobility. Static, } \\
\text { focus on one leg } \\
\text { stance. Four to } 10 \\
\text { different exercises } \\
\text { are available }\end{array}$ \\
\hline $\begin{array}{l}\text { Special } \\
\text { instructions }\end{array}$ & $\begin{array}{l}\text { Incorporated } \\
\text { into or } \\
\text { added to } \\
\text { the } \\
\text { endurance } \\
\text { volume for } \\
\text { long-term } \\
\text { adherence }\end{array}$ & $\begin{array}{l}\text { Weight-bearing } \\
\text { encouraged. } \\
\text { Increase duration } \\
\text { (up to or above } 30 \\
\text { min) before } \\
\text { increasing } \\
\text { intensity up to } \\
\text { moderate }\end{array}$ & $\begin{array}{l}\text { Sets separated by } 1 \\
\text { min; sessions } \\
\text { separated by } 1 \text { day. } \\
\text { Options: free } \\
\text { weights, machines, } \\
\text { elastic resistance } \\
\text { bands, and } \\
\text { calisthenics }\end{array}$ & $\begin{array}{l}\text { No bouncing; PNF } \\
\text { technique; } \\
\text { incorporate into } \\
\text { lifestyle, e.g., } \\
\text { gardening and } \\
\text { putting away dishes } \\
\text { in high and low } \\
\text { shelves }\end{array}$ & $\begin{array}{l}\text { Incorporate into } \\
\text { lifestyle, e.g., } \\
\text { balance exercise } \\
\text { while standing in } \\
\text { line, performing } \\
\text { other tasks; } \\
\text { environmental } \\
\text { safety important }\end{array}$ \\
\hline
\end{tabular}

$H R$ Heart rate, $R O M$ range of motion, $P N F$ progressive neuromuscular facilitation, $R M$ repetition maximum, $R P E$ rate of perceived exertion

${ }^{1}$ For selected older adults for whom vigorous exercise is appropriate and desired, the guideline for vigorous activity is at least 20 min three times/week [30]

regimen. Long-term adherence can be enhanced by making physical activity a part of one's lifestyle [17]. For those wanting to become more active, a group-based physical activity is an excellent way to start a physical activity program [18]. It provides several advantages, including enhanced adherence through social interaction with others and mutual commitment to physical activity among friends, opportunities for instruction in proper technique, and qualified supervision.

\section{Endurance activities}

Endurance-related physical activity refers to continuous movement that involves large muscle groups and is sustained for a minimum of $10 \mathrm{~min} \mathrm{[30].} \mathrm{Examples} \mathrm{of}$ endurance activity include biking, swimming, walking, and lifestyle activities that incorporate large muscle groups. Some examples of lifestyle activities that build endurance when performed for at least $10 \mathrm{~min}$ without rest intervals are household chores such as washing windows, vacuuming, sweeping, and mopping, and gardening activities such as lawn mowing, raking, or pruning. Endurance activities provide the greatest protection against the deleterious effects of chronic diseases associated with aging. While some benefits listed in Table 1 accrue from low-intensity activities [30], progression from low to moderate intensity is important for optimizing the benefits of physical activity.

As new participants become more accustomed to the physical activity, and possibly improve their health, the workload will usually have to be increased to keep the activity at a moderate intensity level. The Borg Rate of Perceived Exertion scale [9] provides an inexpensive and convenient method of measuring physical activity intensity (Table 3). A guide for administering the scale is detailed in the ACSM exercise guidelines book [2]. The talk test is another tool used to evaluate the intensity of aerobic activity and is particularly effective in detecting workloads that 
Table 3 Borg Rating of Perceived Exertion (RPE) scale

\begin{tabular}{ll}
\hline 6 & No exertion at all \\
7 & \\
7.5 & Extremely light \\
8 & \\
9 & Very light \\
10 & \\
11 & Light \\
12 & \\
13 & Somewhat hard \\
14 & \\
15 & Hard \\
16 & \\
17 & Very hard \\
18 & \\
19 & Extremely hard \\
20 & Maximal exertion \\
\hline
\end{tabular}

Borg RPE scale Gunnar Borg, 1970, 1985, 1994, 1998. Correct usage of the Borg RPE scale requires that the participant be trained in the use of the table. Detailed instructions on the use of the Borg RPE scale can be found in the ACSM guidelines for exercise testing and prescription, [2] (p. 79)

rise above moderate intensity. The talk test refers to the ability to engage in conversation while walking or cycling, which is an indication that there is adequate oxygen supply to meet the demands of the respiratory system and the muscle. If the physical activity intensity rises above moderate, talking will become difficult and provide an immediate reminder to reduce the intensity [5]. Evaluating intensity as a percentage of a measure of estimated maximal heart rate (220-age) is the optimal method of tracking exercise intensity. This method is detailed in the ACSM fitness book [3] and several other resources listed in Table 4.

\section{Strength activities}

Strength-related activity refers to increasing muscle strength by moving or lifting some type of resistance, such as weights or elastic bands, at a level that requires some physical effort. Strength development is safe for older adults, and injuries are rarely reported. Instruction in proper lifting technique assists in minimizing injury. Exercise: a guide from the National Institute on Aging provides written and pictorial examples of good form and instruction on proper breathing and lifting techniques [20]. The amount of resistance and number of repetitions will vary for each individual and muscle group. In general, one to three sets of 10 to 12 repetitions are regarded as the optimal amount for increasing muscle strength [4]. As strength increases, the amount of resistance should also increase. Experts do not recommend that strength training be performed on consecutive days to give the muscles time to recover between sessions. While both upper- and lower-body muscles should be included in a strengthening regimen, muscles of the lower body (ankles, hips, leg extensors, and flexors) are particularly important for mobility and independence [26].

Flexibility activities

Flexibility-related activity facilitates greater range of motion around the joint. Flexibility activities increase the length of the muscle beyond that which is customarily used in normal activity. These exercises should be performed a minimum of 2 days a week. In addition to a formal physical activity program, flexibility activities can be conveniently incorporated into the office routine while sitting at a computer or in an airplane. They may be done as a session alone or by inclusion in the cool-down portion of a strength or endurance program [4]. Stretching should include appropriate static and dynamic techniques. In dynamic stretching, the muscle is moved through the full range of motion of a joint, for example, arm circles. A static stretch is when the muscle is lengthened across the joint and held for a period of 10 to $30 \mathrm{~s}$ [2].

\section{Balance activities}

Balance is the ability to maintain control of the body over the base of support so as to avoid falling. While improvements in muscular strength and endurance can lead to improvements in balance, specific balance activities can have additional benefits [11]. There are two types of balance: static balance and dynamic balance. Static balance, as the name indicates, is the ability to maintain balance without moving, while dynamic balance is the ability to move without losing balance or falling. Static balance can be improved by challenging the ability to maintain standing balance through decreasing the base of support. Exercises for static balance can progress from feet apart to feet together and then progress to a single-leg stance without holding on. At first, the person may need to rely on a solid object such as a kitchen counter for support; over time, the reliance on the support will gradually decrease. To challenge balance even further, the above progression can be repeated with eyes closed. The ability to balance with eyes closed is important in daily activities (e.g., standing in a shower while shampooing hair). Dynamic balance can be improved by decreasing the base of support while walk- 


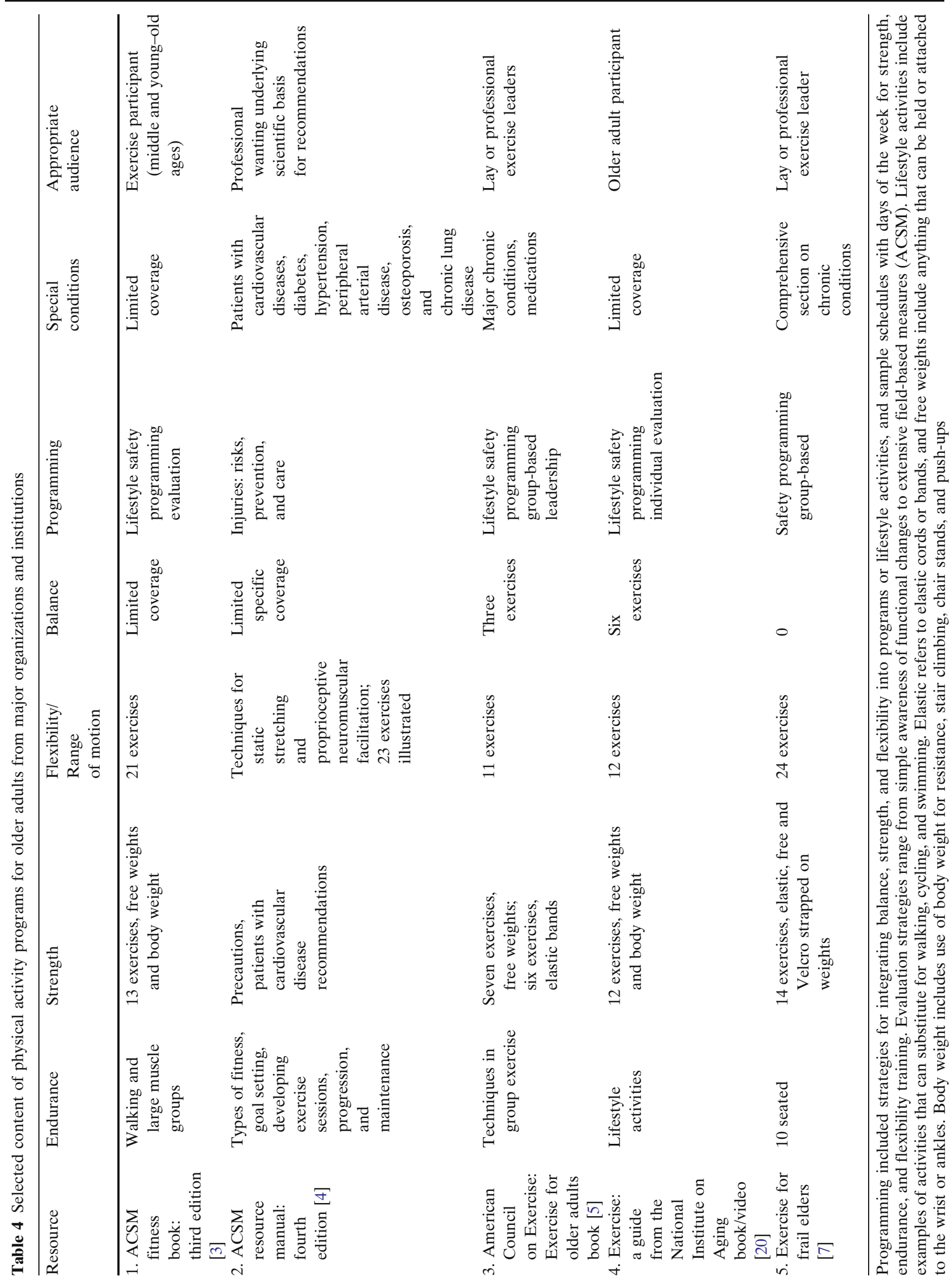


ing. For example, a way to challenge dynamic balance is to progress from the normal walking pattern to walking on a straight line and then walking heel-to-toe.

Some available resources

Although providing detailed exercise techniques and protocols is beyond the scope of this report, many books are available, several of which focus specifically on issues relating to older adults. The National Institute on Aging provides an exercise guide without charge to those contacting the NIA Public Information Office at 1-800-222-2225 or at the website http:// nihseniorhealth.gov/exercise/toc.html. Information provided in Table 4 lists available resources to help plan a physical activity regimen that includes lifestyle activities, age-appropriate exercise, and techniques for leading group exercise.

\section{Section 2: behavioral factors associated with initiating and maintaining physical activity}

Most adults know that regular physical activity is an important component of a healthy lifestyle [1]. However, simply knowing about the importance of physical activity is seldom sufficient to motivate a sedentary individual to initiate and maintain physical activity on a regular basis. A growing body of knowledge suggests that effective physical activity interventions include several well-established principles of behavioral change. Incorporating a comprehensive behavioral management strategy in physical activity interventions can help maximize recruitment, increase motivation for exercise progression, and minimize attrition. The following section provides a brief summary of some of the major factors that increase the likelihood a person will sustain a new physical activity behavior.

Social support. Social support from family and friends has been associated with long-term exercise adherence in older adults [22]. Examples of social support strategies include peer support (e.g., tell a friend and bring a friend, exercise buddy system) and professional health educator support (telephone counseling, mail follow-up).

Self-efficacy. For many seniors, aging is associated with a loss of perceived control [19]. There is growing evidence that people are more likely to initiate and maintain physical activity if they feel confident about their ability to succeed and if they are afforded a variety of opportunities to actively participate in physical activity. Health contracts and having choices (both discussed below) enhance self-efficacy.
Active choices. As part of a comprehensive behavioral strategy, tailoring the exercise program to the needs and interest of participants has successfully motivated older adults to initiate and maintain a routine of regular physical activity [29]. Therefore, physical activity leaders should work closely with individuals to design a physical activity regimen that reflects the person's preferences and capabilities. There is growing evidence that providing choices concerning exercise program characteristics (such as group-based vs individual activity programs and choice of exercise location) contributes to greater adherence.

Health contracts. A health contract is a written agreement negotiated between the participant and a health professional to accomplish a health goal [15]. The contract usually includes realistic goal setting and a measurable plan or course of action for reaching the health goals. The use of a health calendar to record physical activity provides a means for the participant to monitor the targeted physical activity and to reinforce a commitment to the exercise routine.

Perceived safety. Concerns for safety have been identified as a barrier to exercise by many older adults [18]. Physical activity programs can help alleviate inappropriate concerns about safety by educating participants about actual risks of physical activity, and by helping individuals understand how to selfmonitor their exercise intensity levels.

Regular performance feedback. Providing regular and accurate performance feedback can assist older adults in developing realistic expectation of their own progress [21]. Performance feedback should be positive and meaningful to the individual. Observation of meaningful positive changes in performance and success in achieving expected outcomes are associated with exercise adherence in older adults.

Positive reinforcement. Positive reinforcement is any procedure introduced in an intervention that increases the likelihood of maintenance of the activity. Examples of effective reinforcement strategies in physical activity settings include recruitment incentives, rewards for reaching targeted goal, and public recognition for attendance and adherence.

In summary, one or more of these behavioral strategies should be used to facilitate the adoption of physical activity as a lifetime habit.

\section{Section 3: principles of injury and risk management in the general population}

While there are some risks associated with participation in regular physical activity, the risks associated 
Table 5 Emergency procedures and precautions

$\begin{array}{ll}\text { Telephone } & \begin{array}{c}\text { Every facility should have at least } \\ \text { one phone that remains in a } \\ \text { designated location. Instructions } \\ \text { should give the exact location } \\ \text { (street address) and instructions on } \\ \text { what door to enter or other } \\ \text { specifics for that building. } \\ \text { Kit should be available. }\end{array} \\ \begin{array}{l}\text { First aid } \\ \text { CPR and first aid } \\ \text { training }\end{array} \\ \begin{array}{l}\text { Physical activity class } \\ \text { Designated person to get help. } \\ \text { Designated person to take the rest } \\ \text { of class out of the room. Leader to } \\ \text { stay with injured person }\end{array} \\ \begin{array}{l}\text { Telephone tree } \\ \text { Snow days or other reasons to cancel } \\ \text { class } \\ \text { participants with } \\ \text { diabetes }\end{array} & \text { Availability of juice/cookies } \\ \end{array}$

with a sedentary lifestyle far exceed them [8]. Physical activity risks are related to level of intensity, with lower-intensity physical activity being associated with the lowest risk. Low-intensity physical activity reduces the risks of injury and muscle soreness and may be perceived as less threatening than moderateto-high intensity routines. While lower risk is associated with low intensity, the consensus is that moderate physical activity has a better risk/benefit ratio, and moderate-intensity physical activity should be the goal for older adults. Although having an ongoing dialogue with a health care provider is recommended, the involvement of a primary care provider before beginning a program of physical activity depends on a person's health condition(s) and the level of intensity and mode of physical activity. Sedentary older adults typically engage in short sessions $(<10 \mathrm{~min})$ of various types of low-intensity physical activity. There are rarely medical concerns about performing low-intensity activities because virtually everyone engages in them and therefore low-intensity physical activity can be safely performed regardless of whether an older adult has recently had a medical evaluation.

There is no evidence-based strategy to screen for risk before older adults begin or increase their physical activity, so practice depends on the opinion of experts [10, 23, 25]. While some experts and organizations recommend having physical examination and exercise test before beginning or increasing physical activity, exercise tests have a substantial level of false positives for heart disease that may lead to further testing and in turn increase the risk for older adults [14]. Simply having a screening requirement may impose a barrier that reduces the number of people who will begin a program. Because all physical activity is associated with a slight increase in acute injury risk, this small increase must be weighed against the more substantial benefits associated with long-term physical activity. Injury- and riskmanagement strategies should be proportionate to the risks involved, and care should be taken not to discourage participation by establishing overly stringent risk- and injury-prevention programs. For healthy, asymptomatic adults of any age, the US Preventive Services Task Force [31] does not recommend any type of cardiac screening (ECG, exercise test) before the initiation of physical activity. Although ongoing dialogue between a patient and his/her health professional is always desirable, pre-exercise screening by a physician should not be a prerequisite for participation in low-intensity physical activity. For sedentary older people who are asymptomatic, lowintensity physical activity can be safely initiated regardless of whether an older person has had a recent medical evaluation.

Before starting or increasing their level of physical activity, older adults should, however, have a strategy for risk management and prevention of activity-related injuries. Several standard approaches may be used. The most important strategy is to start with lowintensity physical activity and increase the intensity gradually. Whenever possible, physical activity bouts should include a warm-up and cool-down component. Increasing muscular strength around weight-bearing joints, particularly the knee, also reduces the risk of musculoskeletal injury. Other strategies include active stretching during the warm-up and cool-down portions of aerobic exercise programs, participating in a variety of activities, and avoiding high-intensity vigorous exercise. Vigorous activities, including running and jogging and vigorous participation in sports, should be recommended only to older adults who have progressed to and are accustomed to these activities, or who have sufficient fitness, experience, and knowledge required to perform vigorous activities.

Musculoskeletal "overuse" injuries, which can occur at all ages, are the most common and should be the major focus of risk management. Preventing fallrelated injuries, which occur primarily in older adults, is also an important focus for the prevention of injury. Sudden death during exercise is extremely rare, and regular (as opposed to sporadic) physical activity reduces this risk. To minimize the likelihood of injury, changes in physical activity levels should be gradual, not rapid. Programs that allow for a variety of different 
activity choices are most likely to reduce the risk of injuries. Overuse injuries are specific to the activity being performed, that is, someone won't develop tennis elbow from running. So if a person spends 150 min (30 min, 5 days/week) in two different activities, the risk of overuse injuries is theoretically reduced compared to concentrating the entire $150 \mathrm{~min}$ to the same activity.

Every community setting that offers opportunities for physical activity should be prepared to handle an emergency should it arise. Whenever possible, physical activity leaders and other staff should be trained in CPR and first aid. Table 5 lists suggested strategies for emergency preparedness. Written emergency procedures should be developed and posted in a readily accessible location. Although emergency procedures will vary from location to location, most plans will include the following elements: (1) clear instructions on how to access emergency medical services, including directions to the nearest telephone and how to give the exact address and location to the emergency responders, and (2) a well-stocked first aid kit that is readily accessible.

Risk management for adults with chronic conditions and disabilities

Participating in physical activity is an excellent way for older adults with disabilities to maintain their physical function and improve their overall health. All older adults with disabilities should be encouraged to develop a physical activity plan. Based on discussions with their health care provider or exercise professional(s), older adults with chronic conditions or disability should understand the amount and types of activity that are appropriate for them. Preferably, the physical activity recommendation or "prescription" should be documented in the medical record and provided to the patient in writing. The recommendation should be developed proactively at the time of diagnosis of the chronic condition or when a change in clinical condition occurs. Also, the patient should understand that the physician should be consulted if certain problems or questions arise. Regular provider-patient communication about changes in physical activity level is prudent. Physical activity is therapeutic for many chronic conditions, so increasing physical activity levels can be comparable to increasing the dosage of a medication [16]. Unstable medical problems, such as elevated blood pressure or rapid atrial fibrillation, are generally temporary contraindications to exercise. These problems should be diagnosed and treated whether a person seeks to start an exercise program.
Once problems are stabilized, the person can begin or resume exercise.

Because of the wide variety of disabling conditions, describing specific components of an exercise prescription for each condition can be complex. An excellent resource for information about physical activity and disability or chronic health conditions is the National Center for Physical Activity and Disability (NCPAD at http://www.ncpad.org or 1-800-900-8086). Both older adults and health care professionals should consider seeking expert advice when addressing issues related to physical activity in older adults with disabilities.

\section{Summary}

A substantial body of scientific evidence indicates that regular physical activity can bring dramatic health benefits to people of all ages and abilities, and that this benefit extends over the entire life course. Physical activity offers one of the greatest opportunities for people to extend years of active independent life and reduce functional limitations. Regular participation in physical activity is one of the most effective ways for older adults, including those with disabilities, to help prevent chronic disease, promote independence, and increase quality of life in old age.

According to a coalition of national organizations led by the ACSM, a multidimensional activity program that includes endurance, strength, balance, and flexibility training is generally considered to be optimal for older adults. Activities should be tailored to the individual to ensure maximal enjoyment with the goal of optimizing adherence. Although most sedentary individuals should be encouraged to begin with lowintensity physical activity, moderate physical activity yields a better risk/benefit ratio and should be the goal for older adults. Finally, there is a growing body of knowledge to suggest that effective physical activity interventions should combine several well-established principles of behavior change, including: social support, self-efficacy, active choices, health contracts, assurances of safety, and positive reinforcement.

The small increase in acute risk for injury must be weighed against the much more substantial benefits associated with long-term physical activity. Sustaining a physically active lifestyle is an excellent way for older adults with chronic conditions or disabilities to maintain their physical function and improve their overall health. All older adults with chronic conditions or disabilities should be encouraged to work with their health care provider to develop an individualized physical activity plan. 


\section{References}

1. American Association of Retired Persons (2004) AARP exercise attitudes and behaviors: a survey of midlife and older adults. AARP, Washington, DC

2. American College of Sports Medicine (2000) ACSM's guidelines for exercise testing and prescription. Williams \& Wilkins, Baltimore, MD

3. American College of Sports Medicine (2002) ACSM fitness book. Human Kinetics, Champaign, IL

4. American College of Sports Medicine (2000) ACSM's resource manual for guidelines for exercise testing and prescription, 4th edn. Williams \& Wilkins, Baltimore, MD

5. American Council on Exercise (1998) Exercise for older adults. Human Kinetics, Champaign, IL

6. Atienza AA (2001) A review of empirically-based physical activity program for middle-aged to older adults. J Aging Phys Act 9:S38-S55 (Supplement)

7. Best-Martini E, Botenhagen-DiGenova KA (2003) Exercise for frail elders. Human Kinetics, Champaign, IL

8. Booth FW, Charkravarthy MV, Spangenburg EE (2002) Exercise and gene expression: physiological regulation of the human genome through physical activity. J Physiol 543.2:399-411

9. Borg G (1970) Perceived exertion as an indicator of somatic stress. Scand J Rehabil Med 2:92-98

10. Cardinal BJ, Cardinal MK (1995) Screening efficiency of the revised physical activity readiness questionnaire in older adults. J Aging Phys Act 3:299-308

11. Carter ND, Kannus P, Khan KM (2001) Exercise in the prevention of falls in older people. Sports Med 31:427-438

12. Dishman RK, Sallis JF (1994) Determinants and interventions for physical activity and exercise. In: Bouchard C, Shephard RJ, Stevens T (eds) Physical activity, fitness, and health. Human Kinetics, Champaign, IL, pp 214-238

13. Dunn AL, Anderson RE, Jakicic JM (1998) Lifestyle physical activity interventions. Am J Prevent Med 15:398-412

14. Gill TM, DiPietro L, Krumholz HM (2000) Role of exercise stress testing and safety monitoring for older person starting an exercise program. JAMA 284:342-349

15. Haber D, Looney C (2000) Health contract calendars: a tool for health professionals with older adults. Gerontologist 20:235-239

16. Haskell WL (1994) Health consequences of physical activity: understanding and challenges regarding dose-response. Med Sci Sports Exerc 26:649-660
17. King AC (1991) Community intervention for promotion of physical activity and fitness. Exerc Sport Sci Rev 19:211-260

18. King AC, Rejeski WJ, Buchner DM (1998) Physical activity interventions targeting older adults: a critical review and recommendations. Am J Prev Med 15:316-323

19. Kunzmann U, Little T, Smith J (2002) Perceived control: a double-edged sword in old age. J Gerontol B Psychol Sci Soc Sci 57B:484-491

20. National Institute on Aging (1998) Exercise: a guideline from the National Institute on Aging. Report No. NIH 984258

21. Neff K, King A (1995) Exercise program adherence in older adults: The importance of achieving one's expected benefits. Medical Exercise Nutrition and Health 4:355-362

22. Oka R, King A (1995) Sources of social support as predictors of exercise adherence in women and men age 50 to 65 years. Women Health Research on Gender Behavior and Policy $1: 161-175$

23. Olds T, Norton K (1999) Pre-exercise health screening guide. Human Kinetics, Champaign, IL

24. Robert Wood Johnson Foundation (2001) National blueprint for increasing physical activity for adults 50 and older. J Aging Phys Act 9:S5-S12 (Supplement)

25. Shephard RJ (2000) Does insistence on medical clearance inhibit adoption of physical activity in elderly? J Aging Phys Act 8:301-311

26. Singh MAF (2002) Exercise comes of age: rationale and recommendations for a geriatric exercises prescription. J Gerontol A Med Sci Biol Sci 57A:M262-M282

27. Singh MAF (2000) Exercise, nutrition, and the older woman. CRC Press, New York

28. Stewart AL (2001) Community-based physical activity programs for adults age 50 and older. J Aging Phys Act 9:S71-S91

29. Stewart AL, Verboncoeur CJ, McLellan BU, Gillis DE, Rush S, Mills KM, King AC, Ritter P, Brown BW, Bortz WM (2001) Physical activity outcomes of CAMPS II. J Gerontol A Med Sci Biol Sci 56:M465-M470

30. U.S. Department of Health and Human Services (1996) Physical activity and health: a report of the surgeon general. US Department of Health and Human Services, Center for Disease Control and Prevention, National Center for Chronic Disease Prevention and Health Promotion, Atlanta, GA

31. U.S. Preventive Services Task Force (1996) Guide to clinical preventive services, 2nd edn. US Department of Health and Human Services, Washington, DC 